\title{
Optimization of Ventilation and Alarm Setting During the Process of Ammonia Leak in Refrigeration Machinery Room Based on Numerical Simulation
}

\author{
Dongliang Liu, Liang Wang, Tong Wang, Yan Liu, Ya Chen \\ Beijing Municipal Institute of Labor Protection, Beijing 100054, China \\ E-mail:LDLBMILP@163.com
}

Received 22 November 2016

Accepted 16 January 2017

\begin{abstract}
In order to optimize the ventilation effect of ammonia leakage in the refrigeration machinery room, a food processing enterprise is selected as the subject investigated. The velocity and concentration field distribution during the process of ammonia leakage are discussed through simulation of refrigeration machinery room using CFD software. The ventilation system of the room is optimized in three aspects which are named air distribution, ventilation volume and discharge outlet. The influence of the ammonia alarm system through ventilation is also analyzed. The results show that it will be better to set the discharge outlet at the top of the plant than at the side of the wall, and the smaller of the distance between the air outlet and the ammonia gathering area, the better of the effect of ventilation will be. The air flow can be improved and the vortex flow can be reduced if the ventilation volume, the number of air vents and the exhaust velocity are reasonably arranged. Not only the function of the alarm could be ensured, but also the scope of the detection area could be enlarged if the detectors are set on the ceiling of the refrigeration units or the ammonia storage vessel.
\end{abstract}

Keywords: Numerical simulation; Ammonia leakage; Refrigeration machinery room; Ventilation optimization

\section{Introduction}

In China, according to the statistics, over $50 \%$ of the cold storages are built 30 years ago and more than $80 \%$ of the refrigeration machinery rooms choose ammonia as refrigerants ${ }^{1}$. The count from State Administration of Work Safety shows that, from 2005 till now, there have been 24 major accidents of ammonia leakage or explosion happened in China, causing 1171 people injured and 187 people died. Ammonia leakage or explosion is becoming a sensitive issue because its influence to people's life is far beyond its own damage ${ }^{2-}$ 4

Many researchers studied the law of gaseous diffusion by using CFD methods. James S. Bennett ${ }^{5}$ proved that balancing the air inlet and outlet can enhance the control of exposure and pollutant diffusion after simulating the painting process in navy aircraft paint warehouse using CFD software. Galani ${ }^{6}$ studied the concentration of $\mathrm{CO}$ in London using CFD software, finding that the calculated result has a tendency of overestimate because of the uncertainty of urban wind field. Mazzoldi ${ }^{7}$ studied the law of $\mathrm{CO}_{2}$ leakage by CFD simulation method, and the detailed data for the calculation of public safety distance was provided by his result. Chao $\mathrm{C}^{8}$ proved that the CFD method can be used to the standard design by simulating the process of continuous diffusion and the ammonia absorption effect of water spray system. Z.H Guan ${ }^{9}$ simulated how the diffusion influencing factors such as facility layout and the obstacles position affect the diffusion process.

Overall ventilation system is the most important occupational disease prevention facilities in the ammonia refrigeration plant $^{10}$. Numerical simulation method is able to simulate the ventilation effect quantitatively, and it can provide effective guidance to the design and optimization of the ventilation facilities, 
so as to offer data support to the prevention, control and response of ammonia leakage accident in the workplace.

In this research, by using CFD methods, the diffusion process is simulated and its influence factors are studied. Consequences and evacuation after the accidents, ventilation and spraying and other emergency rescue measures are also discussed ${ }^{11}$.

\section{Selection of Numerical Model}

\subsection{Solving equations}

During the process of ammonia diffusion, there is no chemical reaction and it belongs to single phase, multicomponent diffusion. Therefore, continuity equation, momentum equation, energy equation, and component equation are established ${ }^{12}$.

\subsubsection{Continuity equation}

Because the process of ammonia leakage is isothermal process, and the concentration of ammonia gas is different from the air density in the environment, so the continuity equation form selected is:

$$
\frac{\partial \rho}{\partial t}+\frac{\partial}{\partial x_{i}}\left(\rho u_{i}\right)=0
$$

where $\rho$ is the density of the mixed gas, $\mathrm{kg} / \mathrm{m} 3 ; u_{i}$ is the time averaged velocity in different directions, $\mathrm{m} / \mathrm{s}$.

\subsubsection{Momentum equation}

In the inertial coordinate system, the general equation of momentum in direction is:

$$
\frac{\partial\left(\rho u_{i}\right)}{\partial t}+\frac{\partial}{\partial x_{i}}\left(\rho u_{i} u_{j}\right)=-\frac{\partial p}{\partial x_{i}}+\frac{\partial \tau_{i j}}{\partial c_{j}}+\left(\rho g_{i}\right)+F_{i}
$$

where $u$ is the time averaged velocity in different directions, $\mathrm{m} / \mathrm{s} ; p$ is the absolute pressure, and the pressure in the momentum equation is $(p+\rho g z), \mathrm{Pa}$; $\mu$ is the viscosity of the fluid turbulence; $g$ is gravitational acceleration, $\mathrm{m} / \mathrm{s}^{2} ; \rho g_{i}$ and $F_{i}$ are the gravity volume force and other volume forces; $\rho u_{i} u_{j}$ is turbulence stress; $\tau_{i j}$ is stress tensor, defined as:

$$
\tau_{i j}=\left[\mu\left(\frac{\partial u_{i}}{\partial x_{j}}+\frac{\partial u_{j}}{\partial x_{i}}\right)\right]-\frac{2}{3} \rho k \delta_{i j}
$$

\subsubsection{Energy equation}

Because the component transfer model is used, the energy equation must be applied. And its form is:

$\frac{\partial}{\partial t}(\rho T)+\frac{\partial}{\partial x_{i}}\left(\rho u_{i} T\right)=$

$\frac{1}{C_{p}} \frac{\partial}{\partial x_{i}}\left(K_{t} \frac{\partial T}{\partial x_{i}}\right)+\frac{C_{p v}-C_{p a}}{C_{p}}\left[\left(\frac{\mu_{t}}{\sigma_{c}}\right) \frac{\partial c_{i}}{\partial x_{i}}\right] \frac{\partial T}{\partial x_{i}}$

where $T$ is time averaged temperature of fluid, K; $K_{t}$ is thermal conductivity of fluid, $\mathrm{W} /(\mathrm{m} \cdot \mathrm{K}) ; C_{p}$ is specific heat capacity of the mixed gas at constant pressure, $\mathrm{J} /\left(\mathrm{kg} \cdot{ }^{\circ} \mathrm{C}\right) ; \quad C_{p a}$ is specific heat capacity of air at constant pressure in the environment, $\mathrm{J} /\left(\mathrm{kg} \cdot{ }^{\circ} \mathrm{C}\right) ; C_{p v}$ is specific heat capacity at constant pressure, $\mathrm{J} /\left(\mathrm{kg} \cdot{ }^{\circ} \mathrm{C}\right) ; c_{i}$ is mass concentration of mixed gases, $\mathrm{kg} / \mathrm{m}^{3}$.

And there are:

$$
\begin{gathered}
\frac{K_{t}}{K}=\left(\frac{\mathrm{P}_{\mathrm{r}}}{\sigma_{t}}\right) \frac{\mu_{t}}{\mu} \\
\mathrm{P}_{\mathrm{r}}=\frac{\mu C_{p}}{K}
\end{gathered}
$$

where $\mathrm{P}_{\mathrm{r}}$ is the Prandtl number; $\sigma_{t}$ is constant, with interval from 0.9 to 1.0 .

Put formula (5), (6) into formula (4), there is: $\frac{\partial}{\partial t}(\rho T)+\frac{\partial}{\partial x_{i}}\left(\rho u_{i} T\right)=$ $\frac{\partial}{\partial x_{i}}\left(\frac{\mu_{t}}{\sigma_{t}} \frac{\partial T}{\partial x_{i}}\right)+\frac{C_{p c}-C_{p a}}{C_{p}}\left[\left(\frac{\mu_{t}}{\sigma_{c}}\right) \frac{\partial c_{i}}{\partial x_{i}}\right] \frac{\partial T}{\partial x_{i}}$

\subsection{4 component equation}

Multicomponent transport equation without chemical reaction is derived based on mass conservation of components. And its form is: 


$$
\frac{\partial}{\partial t}(\rho \omega)+\frac{\partial}{\partial x_{j}}\left(\rho \mu_{j} \omega\right)=\frac{\partial}{\partial x_{i}}\left(\rho D_{t} \frac{\partial \omega}{\partial x_{j}}\right)
$$

where $\omega$ is component mass fraction; $D_{t}$ is turbulent diffusion coefficient.

And there is:

$$
\frac{D_{t}}{D}=\left(\frac{S_{c}}{\sigma_{c}}\right) \frac{\mu_{t}}{\mu}
$$

where $S_{c}$ is the Turbulent Schmidt number; $\sigma_{c}$ is constant, with general value 1.0.

With $S_{c}=\mu /(\rho D)$ and formula (9), formula (8) is changed as:

$$
\frac{\partial}{\partial_{t}}(\rho \omega)+\frac{\partial}{\partial x_{j}}\left(\rho \mu_{j} \omega\right)=\frac{\partial}{\partial x_{i}}\left(\frac{\mu_{t}}{\sigma_{c}} \frac{\partial \omega}{\partial x_{j}}\right)
$$

\subsection{Project overview}

A refrigeration machinery room in a large food enterprise in Beijing is selected as the research object. It is an old refrigeration machinery room and it covers an area of $550 \mathrm{~m}^{2}$. Its building structure is a layer of frame structure. In the east, west, and north of the building there are solid walls without windows and doors. On the south side of the wall, there are some windows, entrance and exits doors. The clearance height of the building is $7.7 \mathrm{~m}$. There are 2 high pressure ammonia storage devices, 2 horizontal evaporators, 2 low pressure circulating barrels and 2 chain axial flow fans. In this area, the average temperature is $29.9^{\circ} \mathrm{C}$ in July, and the summer dominant wind is from the south, with the average speed of $1.9 \mathrm{~m} / \mathrm{s}$.

\subsection{Geometric model}

Parameters and assumptions of the refrigeration machinery room geometric model are as follows:

- The space size is 17 meters long, 11 meters wide and 7 meters high; the doors size on both west and south side walls is $2.0 \mathrm{~m} \times 1.5 \mathrm{~m}$; the size of the 6 windows on south side wall is $0.7 \mathrm{~m} \times 0.7 \mathrm{~m}$; The diameter of the 2 fans is $0.6 \mathrm{~m}$.

- The model is established according to the actual size and location of the storage tanks. The ammonia pipelines (except the pipelines with leakage), valves, pump body, operating platforms, the cofferdam structure of the liquid ammonia tanks are neglected. The bearing beams on the top of the workshop and the sidewalls except the parts within windows are all considered as the plane walls.

- Supposing that the valve sealing material of ammonia transmission line on the high pressure ammonia storage device has been aging, leading to the micro ammonia leakage. And it is completely volatilized after the leakage. The influence of ambient temperature and humidity is neglected.

- The influence of the fans and the outside wind is considered. Supposing that the wind go into and out of the room vertically, and the wind speed does not change with the height and time.

- As is shown in figure 1, the three-dimensional model is built using GAMBIT2.4

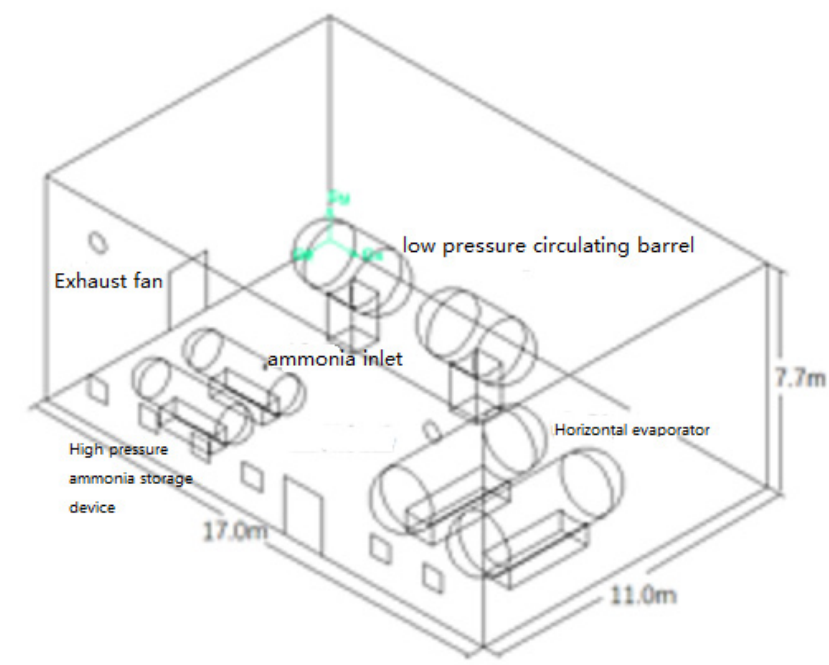

Fig.1.3D Geometric model of the refrigeration machinery room.

\subsection{Boundary conditions and solution parameters}

The reference pressure, gravity and operating temperature are set as $101325 \mathrm{~Pa}, 9.8 \mathrm{~m} / \mathrm{s}^{2}$ and $301.2 \mathrm{~K}$. Ambient air density defaults $1.225 \mathrm{~kg} / \mathrm{m}^{3}$.

CFD simulation parameters and boundary conditions are set as following Table 1 and Table $2^{13-15}$.

Table 1. Calculation parameters setting

\begin{tabular}{rccc}
\hline computational model & \multicolumn{2}{c}{ solving parameters } \\
\hline $\begin{array}{r}\text { turbulence standard } \\
\text { model }\end{array} \mathrm{k} \varepsilon$ & $\begin{array}{c}\text { pressure } \\
\text { velocity } \\
\text { coupling } \\
\text { method }\end{array}$ & SIMPLE \\
\hline $\begin{array}{c}\text { pressure } \\
\text { solver } \\
\text { based } \\
\text { solver }\end{array}$ & $\begin{array}{c}\text { discretizatio } \\
\mathrm{n} \text { scheme }\end{array}$ & $\begin{array}{c}\text { standard / first } \\
\text { order upwind }\end{array}$ \\
\hline $\begin{array}{r}\text { component } \\
\text { transport } \\
\text { model }\end{array}$ & start-up & $\begin{array}{c}\text { convergence } \\
\text { criterion }\end{array}$ & $10^{-3}$ \\
\hline $\begin{array}{r}\text { Energy } \\
\text { equation }\end{array}$ & start-up & - & - \\
\hline
\end{tabular}

Notes: The ammonia leakage rate is derived from the concentration data of the ammonia leakage accident in the enterprise in the past (according to the original data collected from the accident, the ammonia leakage rate is 
about $13 \mathrm{~L} / \mathrm{s}$, which can be exchanged as $0.01 \mathrm{~kg} / \mathrm{s}$ ) and in this leakage rate, the monitoring data are in good agreement with the numerical simulation data. Air exhaust rate is obtained according to the ventilation rate of 12 times $/ \mathrm{h}$.

Table 2. Boundary condition setting

\begin{tabular}{lllll}
\hline position & $\begin{array}{l}\text { boundary } \\
\text { type }\end{array}$ & $\begin{array}{l}\text { measureme } \\
\mathrm{nt}\end{array}$ & $\begin{array}{l}\text { turbulent } \\
\text { coefficient }\end{array}$ & $\begin{array}{l}\text { hydraulic } \\
\text { diameter }\end{array}$ \\
\hline $\begin{array}{l}\text { ammonia } \\
\text { inlet }\end{array}$ & $\begin{array}{l}\text { Mass flow } \\
\text { inlet }\end{array}$ & $0.01 \mathrm{~kg} / \mathrm{s}$ & $4.7 \%$ & 0.05 \\
\hline exhaust fan & exhaust fan & $2.94 \mathrm{~kg} / \mathrm{s}$ & $10 \%$ & 0.6 \\
\hline $\begin{array}{l}\text { door/ } \\
\text { window }\end{array}$ & $\begin{array}{l}\text { pressure } \\
\text { inlet }\end{array}$ & $0 \mathrm{~Pa}$ & $10 \%$ & $1.7 / 0.7$ \\
\hline
\end{tabular}

\section{Analyses of Numerical Simulation Results}

The effect of overall ventilation mainly depends on two factors: ventilation volume and the air distribution in the plant. This section studies the velocity and concentration distribution in the plant by changing the air distribution in the plant, the ventilation volume and the number of air vents.

\subsection{The effect of air flow on the overall ventilation}

The main factors that affect the air flow organization are the position of the air supply and the air outlet and the way of the air distribution. In the most refrigeration machinery rooms, the air comes into them from the doors and windows. And the air trajectory is from the bottom to the top of the building. Therefore, this section mainly considers the effect of the air outlet on the ventilation result. On the basis of the leakage rate and air exhaust volume setting in the former section, the air outlet is arranged on the side of the wall and the top of the building.

Figure 2 is about two vector maps of space velocity field. The setting of the air outlet is the main factor that affects the airflow distribution in the plant, if the ventilation volume and the fan position are definite in different cases. The more uneven distribution of air flow is, the more serious of vortex, the greater the diffusion range of ammonia will be, which indicates that the ventilation effect of exhaust fans is not significant. The air exhaust port is set on the ceiling of the work shop, above the leakage point, which can effectively reduce the diffusion range of ammonia gas. And it is beneficial to the discharge of ammonia gas.
Figure 3 shows two kinds of installation modes of the air vent. Concentration distribution of the ammonia in the air after 10 mins ventilation is shown in the picture. The position of air vent has a significant effect on the concentration distribution of ammonia gas in the whole space. The top exhaust can obviously reduce the ammonia accumulation, the ammonia concentration in the plant, and the diffusion range of ammonia. Therefore, the effect of the top exhaust ventilation is better than that of the side exhaust.

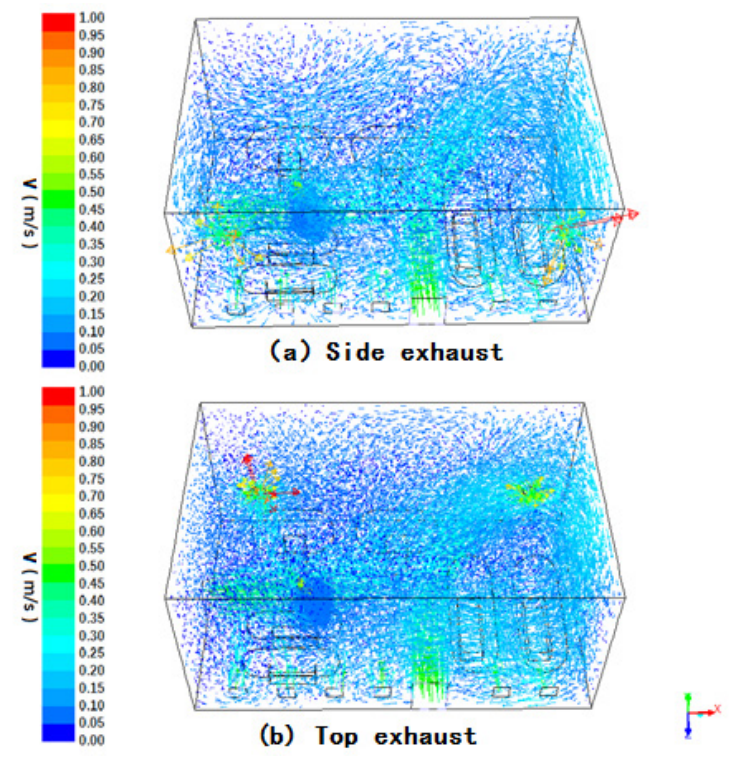

Fig.2. Flow field distribution of velocity vector with different exhaust position.

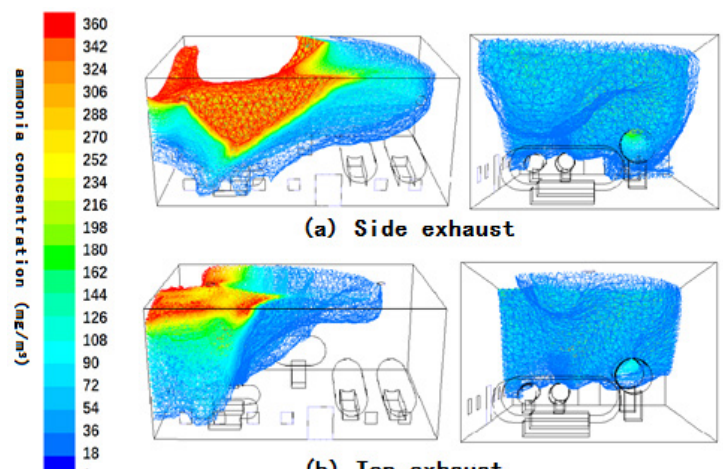

(b) Top exhaust

Fig.3. Distribution of ammonia concentration with different exhaust position. 


\subsection{The influence of ventilation volume on the overall ventilation effect}

According to Code for design of cold storage (GB50072-2010) ${ }^{16}$, air flow rate of accident in ammonia refrigerating plant room should be $183 \mathrm{~m}^{3} /\left(\mathrm{m}^{2} \cdot \mathrm{h}\right)$ and the minimum exhaust air volume should not be less than $34000 \mathrm{~m}^{3} / \mathrm{h}$. According to Code for heating ventilation and air conditioning design of civil buildings ( GB50736-2012) ${ }^{17}$, the air flow of the accident should be determined by calculation according to the process design requirements. And the ventilation should not be less than 12 times $/ \mathrm{h}$. On the basis of the top exhaust setting, the changes of the ammonia concentration field and the velocity field along with the changes of the ventilation rate are observed. The influence of air distribution on the overall ventilation effect is analyzed. Two ventilation plans are as follows, 1) Ventilation 12 times $/ \mathrm{h}$; 2) $34000 \mathrm{~m}^{3} / \mathrm{h}$.

Figure 2 (b) and Figure 4 are vector maps of space velocity field under the two ventilation plans. If the ventilation volume increases, the airflow rate will increase at the air inlet, the air velocity in the whole plant will be greater, and the air distribution will be more uneven, which will be more likely to form a local vortex at the corner of the wall. In the same condition of the installation of air inlet and air outlet, the ventilation volume mainly affects the air flow and the air velocity of the plant. Increasing the ventilation volume, which is conducive to the discharge of ammonia, will make the gas flow inside the plant more complex, however.
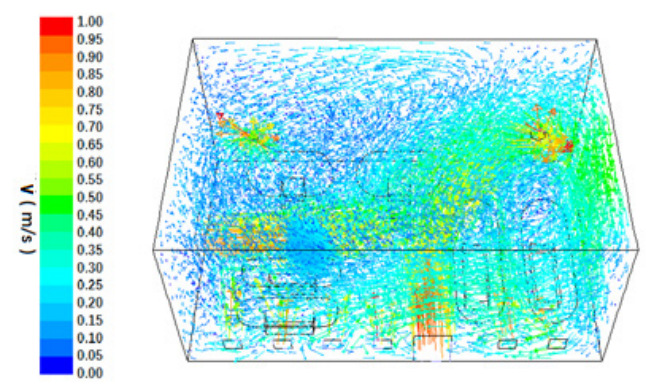

Fig.4. Flow field distribution of velocity vector when Ventilation volume is $34000 \mathrm{~m}^{3} / \mathrm{h}$

Figure 3 (b) and Figure 5 are spatial distribution maps of the ammonia diffusion (400s after the leakage) under the two ventilation plans. Increasing the amount of ventilation volume can significantly accelerate the discharge and reduce the accumulation of ammonia. But in a certain amount of air vents, the greater the air flow, the more complex the airflow inside the plant, the easier it is to form the local eddy current, which will increase the diffusion range of ammonia gas.

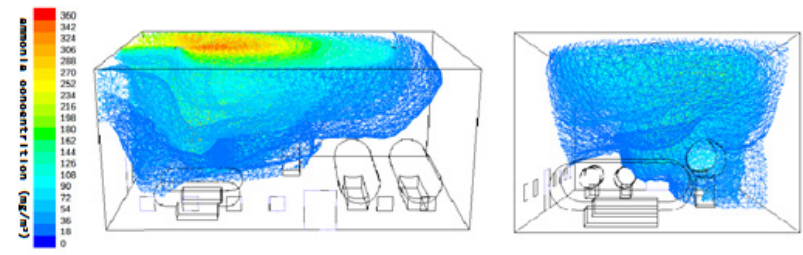

Fig.5. Distribution of $\mathrm{NH}_{3}$ concentration when Ventilation volume is $34000 \mathrm{~m}^{3} / \mathrm{h}$.

\subsection{The influence of the number of air vents on the ventilation effect}

On the basis of the setting of top exhaust and 12 times ventilation mentioned above, ammonia concentration and velocity field distribution are studied by the simulation calculation under the settings of different number (1, 2 and 3$)$ of air vents. Influence of the number of air vents on the ventilation effect is also analyzed by numerical simulation. According to the CFD analysis report, the exhaust rate are $16.9 \mathrm{~m} / \mathrm{s}$, $8.5 \mathrm{~m} / \mathrm{s}$ and $4.3 \mathrm{~m} / \mathrm{s}$ corresponding to the three kinds of settings of the air vents.

Figure 6 is the vector map of velocity field of different number of air vents (1, 2 and 3$)$. If the ventilation volume is certain, the more the number of air vents is, the smaller the air exhaust rate will be. When the air vent number is 1 and 3 , the eddy current is formed in different degrees. When the air vent number is 2, the intake airflow distribution is more uniform and the eddy current is the least, which proves that setting the number of air vents and exhaust velocity reasonably can improve the uniformity of the intake air flow and reduce the eddy current, so as to improve the ventilation effect.

Figure 7 (a), Figure 3 (b) and Figure 7 (b) are the overall spatial concentration distribution of ammonia diffusion in corresponding with number of air vent 1,2 and 3 . The case comparison shows that when there are 2 air vents, the ammonia accumulation and the diffusion area are the smallest, and the ventilation effect is the best. The ammonia gathers at above the leak point. The faster the exhaust air velocity, the closer the distance from air outlet to the gathering area, the more easily the ammonia gas is discharged. It is proved that if the ventilation volume is certain and setting the number of air vents and exhaust velocity reasonably can reduce the eddy current so as to improve the uniformity of the air inlet and the ventilation effect. 


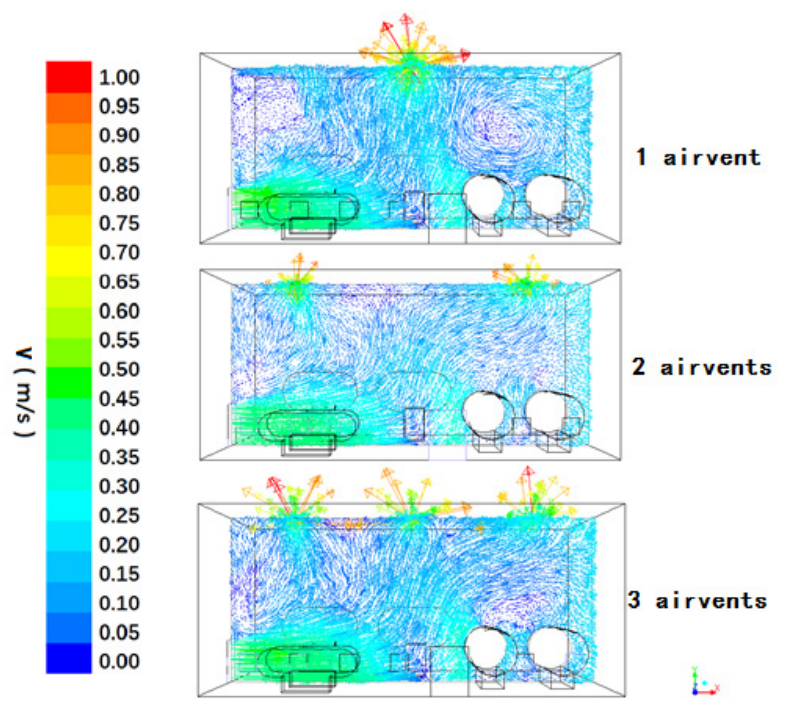

Fig.6. Flow field distribution of velocity vector in the surface of $Z=5.5 \mathrm{~m}$
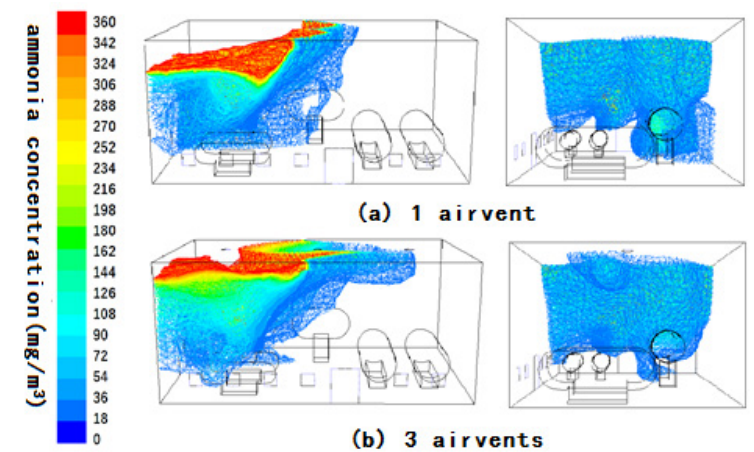

(a) 1 airvent

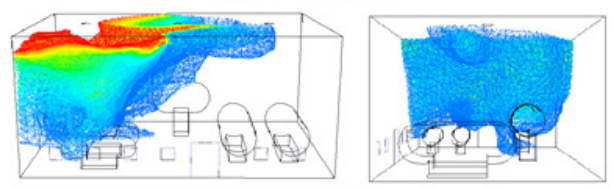

(b) 3 airvents

Fig.7. Distribution of $\mathrm{NH}_{3}$ concentration with different number of outlet

\section{Ammonia Detection and Alarm Setting}

According to the Code for design of combustible gas and toxic gas detection and alarm in petrochemical industry (GB50493-2009 ) ${ }^{18}$, ammonia is poisonous gas. Therefore, ammonia refrigerating plant room should be set with fixed ammonia gas detection alarm and control system according to the specification. So that the accident can be found and the ventilation system can be paused-on in time to reduce the loss.

\subsection{Setting of the alarm value}

According to the data access, as is shown in Table $3^{19}$, there is no uniform provision on the alarm setting value of all countries and regions. The ammonia alarm value in Table 3 is set based on the Code for design of combustible gas and toxic gas detection and alarm in petrochemical industry in China. And the second stage alarm value is much higher than that in other developed countries and regions. Code for design of cold storage is a national code for the development of refrigeration machinery room, which requires that the alarm signal should be automatically sent out, and the accident exhaust fan should be automatically opened when the ammonia concentration reaches $100 \mathrm{ppm}$ or $150 \mathrm{ppm}$. In the engineering design, the ammonia alarm value of the first stage in the refrigeration machinery room is set as $40 \mathrm{ppm}$ based on Code for design of combustible gas and toxic gas detection and alarm in petrochemical industry. And the ammonia alarm value of the second stage is $150 \mathrm{ppm}$. This kind of setting greatly reduces the alarm value of the second stage. And the safety of the personnel is ensured to a great extent.

Table 3. Alarm point of NH3 in different countries or regions

\begin{tabular}{ccc}
\hline country/region & $\begin{array}{c}\text { Value of the first } \\
\text { stage/ppm }\end{array}$ & $\begin{array}{c}\text { Value of the second } \\
\text { stage/ppm }\end{array}$ \\
\hline China & 40 & 100 or 150 \\
America & - & 100 or 150 \\
Hongkong & 25 & 250 \\
Japan & 50 & 200 \\
\hline
\end{tabular}

\subsection{Setting position of the detector}

Code for design of combustible gas and toxic gas detection and alarm in petrochemical industry 4.2 requires that the detectors should be set above the release sauce with the distance less than $1 \mathrm{~m}$ and toxic gas detectors should also be set at the ceiling of the plant 6.1.2 requires that installation height of a detector that detects toxic gases lighter than the air should be higher than the release source, with the distance of $0.5 \sim 2 \mathrm{~m}$. Code for heating ventilation and air conditioning design of civil buildings 7.2.1 requires that ammonia detectors should be installed on the ceiling of the refrigeration machinery room, which is above the ammonia refrigerating unit and ammonia storage container. The standards are not uniform in China. So in the engineering design, there are many ways to set the ammonia detectors in the refrigeration machinery room. In the most of the situations, the detectors are set at the ceiling or above the release source with the distance of 1 2m. In Europe, Japan and Hong Kong, the ammonia detectors are set at the ceiling in the refrigeration machinery room ${ }^{19}$. 
In the refrigeration machinery room researched in this paper, two detectors are set at above the high pressure ammonia storage device, horizontal evaporator and low pressure buffer barrel pipeline valve (with the distance of $1.8 \sim 2.0 \mathrm{~m}$ ) respectively. When the detection points $\mathrm{s}_{1}$ and $\mathrm{s}_{2}$ at above the high pressure ammonia storage device move to the detection points $\mathrm{s}_{1-1}$ and $\mathrm{s}_{2-}$ ${ }_{1}$ at the ceiling of the plant, the change curve of the ammonia concentration along with time is obtained by the optimization model.

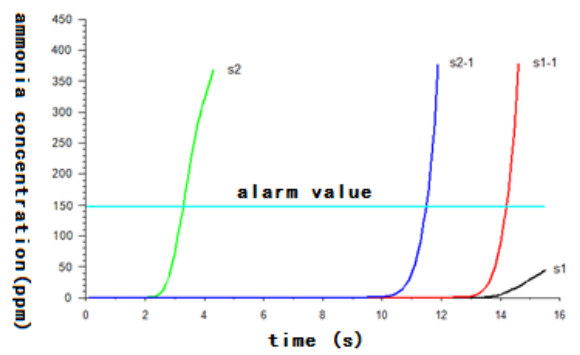

Fig.8. The change of $\mathrm{NH}_{3}$ concentration along with time at the top of the high pressure ammonia storage device

From the time beginning to get the presence of ammonia to the time in theory to cause the alarm, the sequence of time consuming of the four detection points are as follows: $\mathrm{s}_{2}<\mathrm{s}_{2-1}<\mathrm{s}_{1-1}<\mathrm{s}_{1}$. The time it takes in theory at the detection points $\mathrm{s}_{2}$ and $\mathrm{s}_{2-1}$ are $3.2 \mathrm{~s}$ and $11.5 \mathrm{~s}$ with the time difference of $8.3 \mathrm{~s}$. While the response time of the ammonia detector equipment is about 30s, indicating that the time for ammonia diffusion is much less than that for detector response. Therefore, whether the ammonia detector is set at the ceiling of the plant or at above the equipment, the impact it brings on the initiation response time of the alarm and exhaust system is little. As long as the exhaust system can operate normally, the ventilation effect can be guaranteed. Setting the detector at the top of the plant has the advantage of increasing the detecting area.

\section{Conclusions}

- Changing the air flow organization can obviously improve the ventilation effect, the more uniform airflow distribution in the workshop, the less the vortex, the more conducive to the discharge of ammonia, the more effectively the ammonia diffusion region can be reduced. The ventilation effect will be better if setting the air outlet at the top of the plant than that at the side walls of the plant. Reducing the distance between the air outlet and the ammonia gathering area can improve the ammonia removal efficiency.

- Increasing the ventilation rate can obviously accelerate the discharge of ammonia gas, but it will increase the flow of air in the plant to form a vortex, and increase the diffusion region of ammonia gas. Setting the number of air vents and the exhaust velocity reasonably can reduce the vortex and improve the airflow uniformity and the ventilation effect.

- In the ammonia refrigeration machinery room, the first and the second level of ammonia concentration alarm value can be set as $40 \mathrm{ppm}$ and 150ppmrespectively. When the first level alarm is activated, the ventilation system will automatically start and when the second level alarm is activated, all the equipment and facilities of the refrigeration unit will automatically shut down to ensure the safety of the workers.

- Setting the ammonia detection device at the ceiling above the ammonia refrigerating machine and the ammonia storage container in the refrigeration machinery room, not only can meet the alarm requirement, but also can increase the detection region.

\section{References}

1. ZHEN Bing, WANG Lei, GUO Jing, et al. Study on diffusion law of ammonia leakage in cold storage. Heilongjiang Science, 2015,10:4-7

2. WU Xintian. Application of numerical simulation on diffusion of liquid ammonia leak. Tianjin: Tianjin University of Technology, 2014.

3. ZHAO Qingyue. Analyzation on the case of particular serious fire and explosion on 3rd Jun. Baoyuanfeng poultry industry Ltd. in Changchun of Jilin province. Jilin Labor Protection, 2013, 7:32-35.

4. Approval on regarding the agreements of "Investigation report of major ammonia leak accident on 31th Aug. in Weng refrigeration industrial Co Ltd. Shanghai" by Shanghai Municipal Government, No. 90 [2013] HU.

5. James S B, David A M, Duane R. H, et al. Experimental and Numerical Research on the Performance of Exposure Control Measures for Aircraft Painting Operations, Part I. EPHB Report 2011, No.329-12a.

6. Galani A, Neofytou P, Venetsanos A, et al. Prediction and research of pollutant dispersion in a street canyon in London using computational fluid dynamics techniques. Global NEST Journal, 2009,11(4):434-439.

7. Mazzoldi A, Picard D, Sriram P G, et al. Simulation based estimates of safety distances for pipeline transportation of carbon dioxide. Greenhouse Gases: Science and Technology, 2013,3(1):66-83. 
8. ZHAO Huijun, ZHANG Qingsong, ZHOU Shidong, et al. Study on the numerical simulation of gas leakage in gas tank area based on PHOENICS. China Safety Science Journal, 2007,02:39-43+3.

9. Chao C, Wei T, Liu LY, Numerical simulation of water curtain application for ammonia release dispersion. Journal of Loss Prevention in the Process Industries. 2014,30:105-112.

10. CHEN Jiang. Study on the evaluation index of protection effect for ventilation facilities. Journal of Safety Science and Technology, 2013.05:63-66.GUAN

11. Zhong Hui. Liquid ammonia station ventilation safety and influence on leakage and diffusion. Harbin: Harbin University of Science and Technology, 2013.

12. Sorensen DN, Nielsen PV. Quality control of computational fluid dynamics in indoor environments .Indoor Air, 2003, 13: 2 17.

13. WANG Zhipeng. Numerical simulation and emergency response measure for ammonia leakage. Beijing: China University of Geosciences, 2013.

14. YAN Yunfei. Numerical simulation of the influence between spray system and the leaking ammonia accident in the refrigeration station. Harbin: Harbin University of Science and Technology, 2013.

15. YU Jiashou. Liquid ammonia leakage diffusion law and the study of evacuation in open space. Beijing: China University of Geosciences, 2014.

16. GB50072-2010, Code for design of cold storage. Beijing: Standards Press of China, 2010

17. GB50736-2012, code for design heating ventilation and air conditioning in civil buildings. Beijing: Standards Press of China, 2012.

18. GB50493-2009, Code for the design of combustible gas and toxic gas detection and alarm for petrochemical industry.

19. SHI Jichun. Experience learned on the design of explosion-proof and gas-defense in the ammonia refrigeration machinery room. China Refrigeration Association refrigeration freezing Specialized Committee. In 2011 the refrigeration industry and Shandong refrigeration and air conditioning industry annual conference and green low-carbon new technology seminar paper. China Refrigeration Association refrigeration freezing Specialized Committee: 2011:6. 